\title{
Defying Contextual Embeddedness: Evidence from Displaced Women Entrepreneurs in Jordan
}

\author{
Al-Dajani, $\mathrm{H}$
}

http://hdl.handle.net/10026.1/13391

10.1080/08985626.2018.1551788

Entrepreneurship and Regional Development

Taylor \& Francis (Routledge)

All content in PEARL is protected by copyright law. Author manuscripts are made available in accordance with publisher policies. Please cite only the published version using the details provided on the item record or document. In the absence of an open licence (e.g. Creative Commons), permissions for further reuse of content should be sought from the publisher or author. 


\title{
Entrepreneurship \& Regional Development
}

\section{Defying contextual embeddedness: evidence from displaced women entrepreneurs in Jordan}

\author{
Haya Al-Dajani, Hammad Akbar, Sara Carter \& Eleanor Shaw
}

To cite this article: Haya Al-Dajani, Hammad Akbar, Sara Carter \& Eleanor Shaw (2018):

Defying contextual embeddedness: evidence from displaced women entrepreneurs in Jordan, Entrepreneurship \& Regional Development, DOI: 10.1080/08985626.2018.1551788

To link to this article: https://doi.org/10.1080/08985626.2018.1551788

曲 Published online: 16 Dec 2018.

Submit your article to this journal

山 Article views: 68

View Crossmark data ${ }^{\top}$ 


\title{
Defying contextual embeddedness: evidence from displaced women entrepreneurs in Jordan
}

\author{
Haya Al-Dajani ${ }^{a}$, Hammad Akbar ${ }^{b}$, Sara Carter ${ }^{c}$ and Eleanor Shaw ${ }^{c}$
}

aPlymouth Business School, University of Plymouth University, Plymouth, UK; ${ }^{b}$ Management School, Universit of Liverpool, Liverpool, UK; 'Hunter Centre for Entrepreneurship, University of Strathclyde, Glasgow, UK

\begin{abstract}
Although entrepreneurial practices and processes are evolving and changing globally, models of entrepreneurship remain masculinized, embedded in advanced economies and associated with notions of individual agency, heroism and control. Rarely is defiance considered. In this paper, we explore the defiance practices of displaced women operating in the Jordanian patriarchal economy and society and consider how this enabled their nurturing of entrepreneurship. Indeed, we argue that socially excluded women actually defy their contextual embeddedness through their entrepreneurial activities. In so doing, we respond to calls for research that explores the contextual embeddedness of women's entrepreneurship, and contribute to shifting the focus towards the more silent feminine end of the entrepreneurial process. We consider the defiance of invisible displaced women entrepreneurs operating in the under-researched context of Jordan. Longitudinal, ethnographic investigation revealed the creation of a secret production network led by, and for, displaced women. This paper focuses on the five founders of this network, which they established to mobilize and manage the production of traditional crafts and, by so doing, to defy the stifling limitations imposed by their restrictive contractors, community and family members.
\end{abstract}

\section{KEYWORDS}

Women's entrepreneurship; defiance; displaced women; contextual embeddedness; secret networks; Jordan; traditional crafts

\section{Introduction}

At a time when the Middle East region is experiencing significant social, political and economic upheaval, Jordan's small and fragile economy is additionally experiencing the pressure of approximately $30 \%$ of its population being comprised displaced persons requiring aid and support which Jordan struggles to provide (UNHCR 2016). To combat rising unemployment, continuous poverty and social marginalization, displaced women accept contracts to make traditional craft products yet their contracting organizations prohibit them from engaging with other clients and collaborating with other producers. This is despite greater economic returns which can be achieved by multiple client contracts shared between collaborative producers. Longitudinal, ethnographic data collection undertaken between 1999 and 2007 revealed that some women circumvented these restrictive conditions, forming a network of pooled labour delivering craft products to a range of contracting clients. This network operated secretly, masked by the social gatherings of women sharing housework and childcare, hidden from contracting organizations, husbands and other family members (Authors 5). In defiance of terms established by contracting organizations and operating without the knowledge of their husbands and wider families, the founders of this secret 
production network introduced operating efficiencies and generated undeclared surpluses. Just as their heritage craft production has a deeper political connotation in keeping alive a memory of Palestinian traditions lost through displacement, so too their organizing actions are imbued within the deeper purpose of defying their contextual embeddedness by resisting contractual, social and patriarchal subjugation. This paper explores the five founders of a secret production network, and examines the contractual, social and patriarchal defiance exhibited in their proactiveness, innovativeness and risk-taking. We focus upon women's collective defiance utilized to nurture the entrepreneurship of displaced women living in Jordan. As such, we offer an alternative to mainstream masculinized models of entrepreneurship embedded in advanced economies, typically associated with notions of individual agency and control (Hollenbeck, McCall, and Silzer 2006).

Our contribution lies in adding to the growing research on the contextual embeddedness of women's entrepreneurship by extending the theoretical framework of displaced women's entrepreneurship as defiance. We do so by identifying contractual, social and patriarchal types of defiance in the entrepreneurial orientation of displaced women. This is important as present understandings of how displaced women entrepreneurs within patriarchal contexts exercise and exhibit proactive, innovative and risk-taking entrepreneurial behaviours excludes defiance. By forging informal, collaborative secret production networks, the women in our study defy their contextual embeddedness including male domination, authority, institutional norms and barriers, rather than succumb to them.

Following this introduction, the paper starts by reviewing the literature on defiance, resistance and women's entrepreneurship, and the contextual embeddedness of displaced women entrepreneurs. Next we describe the Jordanian context where the research was conducted, and the methodology adopted, before progressing to the research findings relating to the participants' defiance exhibited in proactiveness, innovativeness and risk-taking in founding and maintaining their hidden network and nurturing the entrepreneurship of displaced women. Next we discuss the implications of these findings for advancing entrepreneurship scholarship, before concluding with future research directions focused upon understanding what contextual embeddedness means for invisible, marginalized communities.

\section{Defiance, resistance and women's entrepreneurship}

Defiance is the daring and bold disobedience towards authoritarian regimes such as patriarchy, and/or opposition to forces such as established cultural norms. Defiance is active, explosive and volatile and cannot be passive or placid. It is exercised through dismissing prescriptions, challenging and/or contesting imposed institutional norms (Pache and Santos 2010). As such, defiance differs from resistance which involves efforts to oppose or refuse to cooperate with, or submit to abusive behaviour and control (Profitt 1996). While resistance can be active (Kandiyoti 1988) and explosive (see Kark 2004), it can also be passive when the aim is to overcome or circumvent barriers and unfavourable norms (Javadian and Singh 2012). Resistance may not involve rejecting or eliminating constraints, whilst defiance necessarily involves a higher behavioural intensity, such as the downright rejection of constraints (Pache and Santos 2010). Defiance involves a deeper level of action and intensity and represents a more active form of resistance (Welter and Smallbone 2010).

We define entrepreneurship as an act of defiance that can create new opportunites and execute in uncertain and unknowable environments, to generate economic, social and personal value (Neck and Greene 2011). Defiance is implicit in Schumpeterian notions of 'creative destruction', whereby entrepreneurship disrupts the existing equilibrium by shifting economic activity by engaging in innovation which disrupts the status quo. Similarly, women's entrepreneurship can be an act of defiance althouth it has rarely been framed as such. In other research arenas, female defiance has featured within domestic violence (Koss 2000), feminist scholarship and activism (Murphy 2015) and art (Chhiba 2013). Research on women's corporate careers, and pathways to leadership in 
education, has also focused on defiance. Curry (2000) for example, showed how women constructed themselves as leaders by defying the traditional, male-dominated cultural norms to move towards self-efficacy in the workplace. Similarly, Basit (1996) highlighted how young British-Asian, Muslim women defied their working class location aspiring for occupations which were unambiguously middle class.

We position defiance as implicit and embedded in the entrepreneurial effort of 'breaking up' perceived constraints as well as 'breaking free' from existing authority (Rindova, Barry, and Ketchen 2009), and consider entrepreneurial orientation as an attitudinal mindset manifested in the enactment of innovative entrepreneurial ventures. In breaking up constraints, the entrepreneur defies her comfort zone opting for proactiveness - defined as an opportunity-seeking and forward-looking perspective, involving acting in anticipation of future problems, needs or changes, to actively exploit environmental opportunities (Bolton and Lane 2012). Welter (2011), for example, showed that women entrepreneurs in the Ukraine use their female identity to mirror tax inspectors' perceptions of them as weak and ensure they paid minimal tax penalties. These women exploited environmental opportunities by acting in anticipation of future need (e.g. to save resources), suggesting that contractual defiance is closely associated with proactiveness. In breaking free from authority, the entrepreneur defies 'existing prescriptions' and instead opts for innovativeness - defined as the ability to think imaginatively and engage in new ideas and experimentation to develop novel and useful ideas (Kreiser and Davis 2010). Welter and Smallbone (2010), for example, highlight how women entrepreneurs in Uzbekistan reduced dependency on the assistance from their families by developing their own contacts - a role that widowed and young women are not traditionally expected to play. These women were able to think imaginatively and develop new solutions to enduring problems, suggesting that social defiance is closely associated with innovation. The entrepreneur also defies 'risk aversion' and instead opts for risk-taking - defined as the willingness to absorb uncertainty in the wake of an unpredictable future by taking bold action by venturing into the unknown (Bolton and Lane 2012). Jamali (2009) showed that in the context of Lebanon, women initiate new ventures in defiance of their husbands who were not entirely convinced of their ability to break through the social and patriarchal barriers and succeed. These women took bold action by venturing into the unknown, suggesting that patriarchal defiance is closely associated with risk-taking. Nevertheless, the implicit and embedded defiance in entreprepreneurship has yet to be analytically explicated and applied to researching and understanding women's entrpreneurship. We attempt to bridge this gap within our research as we seek to analyse the entrepreneurial innovativeness, proactiveness and risk-taking of displaced women through their contractual, social and patriarchal defiance. In doing so, we offer a novel approach to analysing displaced women's contextually embedded entrepreneurship.

\section{The contextual embeddedness of defiant displaced women entrepreneurs}

The literature on women's entrepreneurship and defiance remains small and focused on women who are citizens or nationals, rather than displaced women. For example, Welter and Smallbone (2010) discussed how women in post-Soviet societies actively defied the cultural norms which ascribed them to defined feminine roles hindering their entrepreneurial activities. Similarly, Chamlou (2008) suggested that female-owned firms in the Middle East and North Africa region represent a defiance of the stereotypical societal expectations of women. The defiance of women entrepreneurs was also implicit in the case narratives from Pakistan where women established successful ventures and interacted with male entrepreneurs despite a volley of criticism from relatives and hostile attitudes from male colleagues (Goheer 2003). Similarly, defiance was implicit in Ahmad's (2011) study highlighting how women entrepreneurs in Saudi Arabia were able to compete with male counterparts who regarded them as submissive and docile.

Entrepreneurship among displaced women is more often grounded in the women's empowerment paradigm (Goyal and Parkash 2011) which argues for greater access to, and control over, 
economic and social resources (Kabeer 1999). Displaced women in highly patriarchal, restrictive contexts enact their empowerment through defying their contextual embeddedness (Authors 5). For them, entrepreneurship requires defying institutional norms, social barriers and stereotypical attitudes such as social exclusion within the community and restrictions on movement (Ahmad 2011). In so doing, entrepreneurship becomes a catalyst for their defiance and subsequent empowerment, as it facilitates an otherwise unattainable success (Al-Dajani and Marlow 2013). However, given the contextual embeddedness of the structured social and gender relations, limited agency arising from the patriarchal context, and their positioning through social exclusion, impoverishment and displacement, their defiance must be camouflaged, for example through the creation of hidden, secret networks.

Not only is research on women's leadership within business networks scarce, where it has been studied the context has typically been in corporate sectors and the focus on formal networks (Hopkins et al. 2008). An exception is Torri (2012), who studied an Indian, women-led communitybased enterprise and women's visible, informal networks. She argued that networks of self-help groups have particular challenges and as such must not become the paradigm in development policies for women entrepreneurs. To date, research on hidden organizing and networks is extremely limited (Stohl and Stohl 2011) and similarly, women's leadership of informal, secret or hidden networks is a rare topic (Authors 5). Given that informal networks in patriarchal contexts are generally gender exclusive, they offer rare opportunities for women's entrepreneurial leadership. A deeper understanding of how women develop and exercise their leadership at individual and organizational levels within informal, hidden entrepreneurial networks, and how this agency compares with existing conceptions of leadership that largely originate from advanced economies and corporate contexts will enhance our understanding of women's entrepreneurship in informal and developing contexts more broadly.

In reviewing influential entrepreneurship journals and their publications on Arab women in the Arab Middle East over the last 10 years, only 14 articles were found, and only 3 addressed displaced women (Al-Dajani and Marlow 2013; Al-Dajani et al 2015). To date, few studies have considered the entrepreneurial behaviours of displaced women or the defiance inherent in these. As such, this paper contributes to the literature on contextualizing women's entrepreneurship (Henry et al. 2015; Yousafzai, Saeed, and Muffatto 2015) by considering the defiance of displaced female entrepreneurs operating in the under-researched context of Jordan; a culture with influential gendered power structures where displaced women entrepreneurs are rarely recognized as entrepreneurs or entrepreneurial leaders. Given the prevalence of displaced and disadvantaged women producing traditional crafts such as embroidery in developing economies (Chamlou 2008), we consider how defiance nurtures this with strong, yet previously unacknowledged links.

\section{The Jordanian context}

Jordan ranks within the world's largest five refugee host countries (UNHCR 2016), yet it has neither ratified the 1951 United Nations Convention on the Status of Refugees, nor the 1967 Refugee Convention Protocol (Stevens 2009). However, Jordan continues to accommodate its communities from neighbouring countries that have become displaced through war and violence, offering shelter, safety and security, although its economic resources are extremely limited (Gandolfo 2012). Indeed, in the most recent Legatum Prosperity Index benchmarking wealth and wellbeing Jordan ranked 89th out of 149 countries (Legatum Prosperity Index 2016).

Jordan's population of 9.5 million includes 2.9 million displaced persons $-30.6 \%$ of the country's population (Jordan Department of Statistics 2016). Contrary to popular belief, the vast majority of the 1.4 million displaced Syrian nationals (UNHCR 2016), 300,000 displaced Iraqi nationals (Chatelard 2009) and 2 million displaced Palestinians (UNRWA 2014) reside predominantly within the capital and other urban centres such as Irbid, Mafraq and Zarqa, and not in refugee camps (Habersky 2016). All displaced nationals live legally in Jordan, but are denied full citizenship rights 
including employment and benefits as their residency is categorized as temporary - even when they and their descendants have lived in Jordan for decades (Stevens 2009). Legal restrictions on employment, coupled with Jordan's high unemployment rate (Fanek 2015), have largely confined the economic activity of displaced persons to the boundaries of the informal economy (Al-Dajani et al 2015).

In this paper, we focus on displaced Palestinian women. Displaced Palestinians have resided in Jordan for over 40 years - much longer than any other displaced group. While institutional interest in Palestinians has been diverted to more recently displaced populations such as the recently arrived Syrians, this group do have one remaining support channel - over 2 million Jordanian full citizens of Palestinian origin (UNRWA 2010) who generally arrived in Jordan pre-1967, and their offspring (Gandolfo 2012).

\section{Methodology}

Discovering, accessing and infiltrating hidden populations is challenging, with complex ethical research implications (Minkler and Wallerstein 2010). A hidden population is defined by Heckathorn $(1997,174)$ as a population where 'no sampling frame exists and public acknowledgment of membership in the population is potentially threatening' to members. We define the collaborative secret production network that emerged in this study as a hidden population since there are no available data on its existence, the overall number of women engaged within it as producers and consumers is unknown except to the five founders and leaders of the network and there exist genuine social and economic threats to its participants if they were identified.

Snowballing strategies are often used and recommended (Liamputtong 2006) for accessing hidden populations as is targeted sampling (Goodman 2011). These approaches however are suitable when the existence of the hidden population is already known to the researcher. Approaches for discovering unknown, invisible and hidden populations remain rare in the available exploratory research methodologies literature. As we were unaware of the existence of the collaborative secret production network when we embarked on this research, the adopted longitudinal approach was fundamental in revealing this as it fostered trust between the participants and the lead researcher. The Arabic-speaking lead researcher conducted the interviews and gained the participants' trust as they became more familiar with her as they progressed from one interview to the next. The existence of the collaborative secret production network was revealed by its five founders 3 years after the initial interviews were conducted. Given the research benefits of longitudinal methodologies and their limited implementation in entrepreneurship research, especially in developing and emerging economies, there are encouraging calls for their adoption in entrepreneurship research (Al-Dajani et al 2015; Kiss, Danis, and Cavusgil 2012).

\section{The participants}

At the start, 27 organizations contracting displaced home-based women producers operating in Jordan were approached to participate in a study exploring women's empowerment and entrepreneurship and to provide access to their home-based displaced, Palestinian women producers. Eight organizations agreed, and to avoid their potential bias in participant selection, the researcher attended each participating organization to greet the home-based producers as they arrived to deliver their products and invited them to participate. This method proved to be most effective in securing agreement to individual interviews from 43 home-based displaced Palestinian women producers of whom 3 were divorced. By the completion of the study in 2007, the participants were aged between 26 and 64 years, and were mothers to an average of three children. Whilst the majority (28) had completed secondary education, 14 participants completed primary schooling only, and one participant was a university graduate. About their home-based production, by the 
end of the study in 2007, the participants had on average supplied their intermediary organizations for 15 years.

\section{Data collection and the relevant discoveries}

The 8-year longitudinal study comprised three consecutive stages of data collection involving semistructured individual interviews with the 43 displaced home-based women producers culminating in a total of 129 semi-structured interviews. Stage 1 of the data collection revealed that five contracting organizations through which the participants were accessed, restricted their suppliers' engagement with other producers, clients and businesses, even when the contracts they commissioned were minimal. This finding was later verified and justified by the contracting organizations and discussed in Al-Dajani and Marlow (2010) and Al-Dajani et al (2015). While this finding was not anticipated at the design stage of the study, it was accounted for through the inclusion of relevant questions to the interview guide used in the second stage of the data collection. Overall, 28 of the 43 participating displaced home-based women producers were contracted by these five restrictive organizations. Their prospects of simply finding alternative work models were almost negligible due to their 'displaced' sociopolitical status.

By the end of the second stage of data collection, the unanticipated phenomenon of the collaborative secret production network emerged. Five participants; Jalila, Lubna, Muna, Sundos and Ghalia (alias names used) trusted and confided in the researcher by taking the decision to reveal and declare their creation and leadership of a collaborative secret production network that defies the restrictions imposed on them by contractors, families and others.

As a result, Stage 3 of the data collection focused on these women's motivations for establishing and maintaining this secret network, and their evolving defiance through their proactiveness, innovativeness and risk-taking. This shows the benefits of longitudinal research with underresearched and under-reported populations, and for revealing unexpected and emergent phenomena. Our discussion of these findings seeks to contribute to a research gap concerning the role of defiance in displaced women's entrepreneurship in developing economies and within sociopolitically displaced and marginalized populations. The secret network and its dynamics were presented in Al-Dajani et al (2015).

\section{The founders of the secret production network}

The relationships between the five network founders predated their marriages and engagement in home-based enterprise, through school, family and friends. All five women lived within the same community and were connected through birth family and friendships. Table 1 shows that Sundos was the eldest of the founders, and completed primary education only, 'to stay at home and look after my younger brothers and sisters while my parents went to work' (Sundos). Similarly, Lubna the youngest of the founders and Sundos's cousin, also terminated her education at the end of primary school 'to help my mother and sisters with embroidering' (Lubna). In fact, Sundos was taught to embroider at the age of 9 by her aunt and proudly sold her first embroidery item at the age 13 .

Table 1. Profiling the network founders and leaders.

\begin{tabular}{lccccccc}
\hline Name & Age & $\begin{array}{c}\text { Born in } \\
\text { Jordan }\end{array}$ & $\begin{array}{c}\text { Education } \\
\text { level }\end{array}$ & $\begin{array}{c}\text { Marital } \\
\text { status }\end{array}$ & $\begin{array}{c}\text { Husband also displaced } \\
\text { person }\end{array}$ & Children & $\begin{array}{c}\text { Years supplying restrictive } \\
\text { organization }\end{array}$ \\
\hline Jalila & 44 & No & Secondary & Divorced & Yes & 1 & 17 \\
Lubna & 31 & Yes & Primary & Divorced & Yes & 2 & 13 \\
Muna & 42 & No & Secondary & Divorced & Yes & 3 & 18 \\
Sundos & 45 & No & Primary & Married & Yes & 4 & 13 \\
Ghalia & 34 & Yes & Secondary & Married & Yes & 3 & 11 \\
\hline
\end{tabular}


Table 1 shows that all five displaced women had supplied their respective contracting organization for over 10 years and planned to continue. They all agreed with Muna's statement that 'through this work, I am able to know what is happening in the market, the events, the trends, the prices, the embroiderers ... it helps us to keep an eye on our work and clients'.

Table 1 also shows that three of the five founders; Jalila, Lubna and Muna were divorced. In a society where divorce is both rare and frowned upon, these women faced significant social marginalization within their own communities. As Lubna explained, 'My participation in this circle is not a choice, I have to ... as a divorcee where else can I get support from? How will I feed my children if I don't embroider?'

\section{Data analysis}

The qualitative thematic analysis undertaken for this paper focused on the data collected from the five displaced women network founders in Stages 2 and 3 of the longitudinal study. This allowed for an in-depth consideration of the evolution of the women's defiant proactiveness, innovativeness and risk-taking in managing and growing their hidden network to nurture the entrepreneurship of other displaced women.

Qualitative analysis software such as NVivo remains unreliable for 'right to left' languages such as Arabic. To overcome this, the Arabic-speaking lead researcher conducted the thematic analysis and first-, second- and third-order coding process (Gioia, Corley, and Hamilton 2013; Miles, Huberman, and Saldaña 2013) manually by utilizing the Arabic interview transcripts. Quotes presented in this paper were translated to English by the lead researcher, and later back-translated into Arabic by another professional bilingual Arabic - English researcher external to the research team. This practice aided the accuracy of the English translations presented in this paper.

\section{Ethical considerations}

Protecting the identities of the participants and their collaborators was paramount due to the social and economic threats of exposure. This was achieved by anonymizing all participants' identities, concealing the identities of the contracting organizations and placing an extended time lapse of 10 years between the completion of the data collection and publication. During this period, the vast majority of managerial staff within the restrictive organizations have transferred to other positions and are no longer a threat to the participants of the study. Furthermore, the restrictive organizations are now impossible to identify due to the number of new organizations that have entered the sector. In addition, given the saturation of the sector, exacerbated by the arrival of displaced Syrians in Jordan since 2011, displaced Palestinian women have become increasingly ignored, and are thus able to continue their hidden entrepreneurship away from any spotlight. Indeed, to ensure that this research did not ignite any concerns or doubts among the restrictive organizations, the researchers did not discuss the emergent theme of the hidden network with them. Consequently, while our priority is the well-being of the participants, we remain unaware of the extent of knowledge of the hidden network among the personnel of the restrictive organizations.

\section{Findings}

To critically analyse entrepreneurship and defiance amongst displaced women, the findings focus on the five founders of the secret production network, and explore the three dimensions of proactiveness, innovativeness and risk-taking, through the women's contractual, social and patriarchal defiance. In so doing, we contribute a new meaning embedded within the concept of defiance to women's entrepreneurship.

While the results show defiance as an integral characteristic of the displaced women's entrepreneurship, initially the five leaders appeared to conform to stereotypical images of poor, 
displaced women, subjugated and dominated within a traditionally patriarchal culture, and did not appear to emanate defiance. However, their interviews during Stages 2 and 3 of the data collection revealed unexpected insights. The ensuing results and discussion below demonstrate how entrepreneurship is a process of defiance that evolves over time, rather than a pre-existing characteristic. Table 2 also shows how proactiveness, innovativeness and risk-taking are matched with the participants' demonstrated contractual defiance, social defiance and patriarchal defiance which are embedded in the participants' various actions.

\section{Contractual defiance}

The five leaders reported motivations for proactively creating the secret network 2 years after Ghalia began supplying her restrictive organization. These were overcoming the restrictions imposed by the contracting organizations, preserving their lost heritage and providing support to each other. However, none of the women stated leadership as a motivation for establishing their network. Collectively, the stated motivations demonstrate the proactiveness, innovativeness and risk-taking of the participants in breaking the terms of their contracts (contractual defiance). They all agreed that overcoming the imposed restrictions by their contracting organizations, was a key motivating factor for establishing their hidden network. Lubna explained, 'we are the expert embroiderers and their profits depend on our work. Yet, they strangled us with their control, we had to fight back somehow or we would have given up embroidery altogether'.

Not only did the five women break their own contracts with their organizations by undertaking embroidery for other clients and organizations, they recruited other women to do so and grew their secret network. Recruiting members to the secret network was simple and straightforward as described by Sundos:

it was very natural for me to recruit other women supplying the same organisation as me, we had known each other forever, they all live nearby, we all suffer from the same frustration with the organisation, and we anyway, already helped each other out with some of the contracts.

However, monitoring and managing the growth of the network was challenging and required risktaking as initially, the women leaders neither expected nor envisioned the apparent growth. 'We just knew that whatever we did, we had to keep our network hidden to keep ourselves and all our members safe' (Ghalia, Stage 3).

In addition to recruiting embroiderers to their secret network, the five leaders were responsible for securing clients and contracts to increase the production and profits for all their members. Given the number of years that Sundos and Muna had been embroidering, they shared an extensive list of contacts and clients and, Jalila, Ghalia and Lubna had access to unique market intelligence as the restrictive organizations they worked for are recognized throughout the Middle East region for their high-quality products. Thus, innovativeness was a critical aspect of their contractual defiance because 'when we approach potential clients, or are approached by them, they are very impressed by the quality of our work but also by how much we know about our market' (Jalila, Stage 3).

All women agreed that heritage preservation was a key motivator for contractual defiance. Ghalia's statement chimed with the four other leaders; 'we were all taught embroidery here by our mothers, aunts, neighbours, and they were taught by their grandmothers, mothers and aunts in their villages in Palestine. This art is our history and our future'. From the time when they established the secret network, the five leaders recognized that the feminised traditional embroidery sector in which they operate remains highly saturated and intensely competitive (Al-Dajani and Marlow 2010). This is explained in Lubna's statement that, 'we cannot compete with them [contracting organisations] openly, they will eat us alive!' Whilst the five leaders were defeating their restrictive organizations through their growing secret network, they were also terrified from their powerlessness, but nevertheless, took the risks. Overcoming this powerlessness through supporting each other was also a motivating factor for contractual defiance. Sundos and Ghalia 


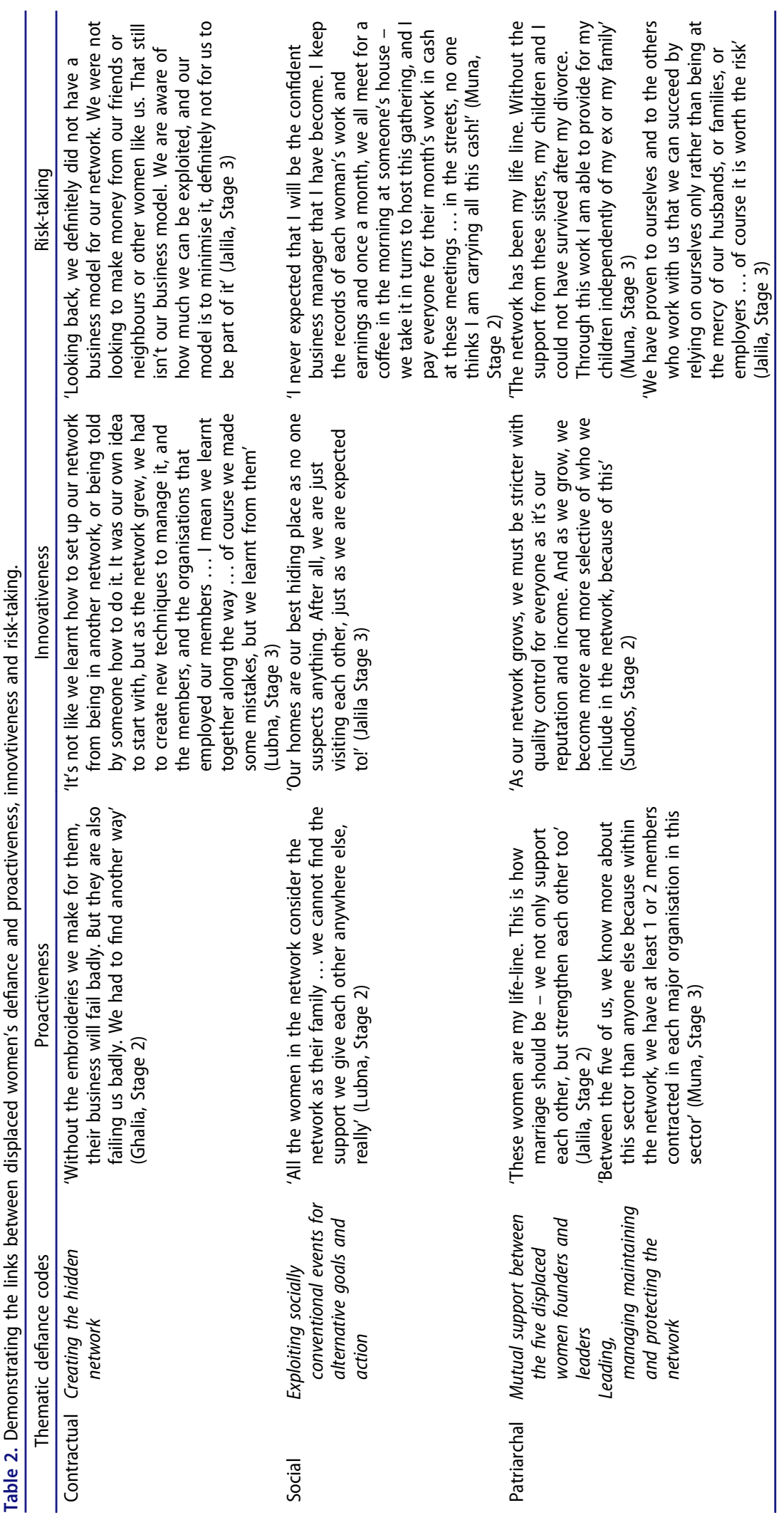


agreed that 'we just knew that whatever we did, we had to keep our network hidden to keep ourselves and all our members safe' (Ghalia, Stage 2).

For the three divorced leaders, obtaining financial independence to provide for themselves and their children, was a key motivating factor for contractual defiance, whilst Sundos and Ghalia who remained married, enhancing their income was cited as a motivating factor for contractual defiance through the creation of their secret network.

\section{Social defiance}

Residing and operating within a collective community, the five leaders quickly identified the perfect cover for their secret production network. Each leader developed a schedule for her members, and regularly met at a different member's home. These women's social gatherings were an accepted and expected part of the local culture but the members of the secret production network dedicated this time to shared production rather than socializing. Thus, the women innovatively defied social expectations and exploited the gendered social norms. Sundos explained that

everyone is used to seeing us going to each other's houses, they think we are preparing pastries, stuffing vine leaves or picking parsley for tabbouleh. There are no suspicions. Anyway, a few of us will be doing these things while the rest of us get on with the embroidery... I rotate the duties depending on the embroidery stitches, number of items that need to be made and especially the cooking as some women's cooking is not as good as their embroidery!

Through these gatherings, the women shared embroidery production, childcare, cooking, and other chores to ensure that their domestic responsibilities were not overlooked as this could lead to unnecessary curiosity and questioning from the broader community. While there is no evident innovativeness in the women's embroidery since they chose to maintain the authenticity of it, the secret network itself is an indication of the women's proactiveness, innovativeness and risktaking. Through their network, the women defied the social norms that restricted their mobility, employment, community engagement and wealth creation, and fulfilled their aim of shared financial, emotional and social support between network members. All five leaders reiterated Lubna's (Stage 3) statement that 'our network has become a fundamental of every member's life ... without it, our lives would be terrible ... we now have such strong bonds with each other, its genuine solidarity and friendship, not just work'.

\section{Patriarchal defiance}

The five leaders operated their network in a patriarchal community and culture which imposed stringent regulations to maintain the dominant gender norms. These regulations determined the women's mobility within and beyond the community, their education, employment, enterprise, wealth creation, and community engagement. Creating and maintaining a sustainable hidden network of women producers certainly challenged these patriarchal gendered norms, and the potential exposure of the network put the women at great risk. All five women agreed that the prescribed gender roles within their patriarchal community determined their actions as well as others' judgements of them. Ghalia explained, 'if my father-in-law found out that I was organising other women in our neighbourhood and working with them without the contractor's knowledge, he will immediately ask my husband to divorce me because decent and respectable women don't behave like this'. Sundos added, 'they [family members and in-laws] worry that we will challenge them and their power over us too. Of course we do this already, but what they don't know won't hurt them or us!' Thus, in creating and maintaining the secret network, the five leaders were taking a great risk with their livelihoods.

Aware of their risk-taking through their contractual, social and patriarchal defiance, the five women continued to operationalize their hidden network, and grow it secretly through a 
fragmentation strategy. They crafted measures to minimize the risk of their network's exposure, and continuously risked the potential exposure when recruiting new members, customers and clients. To operationalize the fragmentation strategy effectively, trust between the women leaders was critical as each was responsible for recruiting home-based producers supplying her restrictive organization.

'In this way, the women from each organisation didn't know that there were other "outsiders" involved' explained Lubna. 'This strategy was first suggested by Jalila, but we all agreed because it meant we all had the same responsibility to make it work' (Sundos).

Thus, the leaders' management approach was to fragment the overall network, and for each leader to manage and grow her pool of members. Muna explained that this was not by design:

we didn't deliberately choose to embroider for different organisations. I'm sure none of us thought about this at the time. Now that you mention it, I guess it was meant to be, because if we all embroidered for the same organisation, we would not have met all the embroiderers and clients that we have now.

Ghalia and Lubna however, agreed that 'at the time, I definitely did not want to embroider for the same organisation as my sister's friends' (Ghalia). Ghalia explained that '... you never know what happens and the last thing I wanted is for Iman [Ghalia's sister] to find out about my work from Jalila or Muna'. Trust between the five women grew over time as they supported each other, and worked closely on establishing and growing the network. Both Ghalia and Lubna agreed that 'now it is different. I love working with all of them, they are sisters to me and we have no secrets between us' (Lubna).

The network fragmentation strategy appears effective for minimizing the risk to exposing the hidden network, for maintaining cover and controlling membership, the network operations, members' interactions with each other, and clients' access to the network. However, it may have also helped to keep the secret production network hidden from others who might be threatened by it. This included other embroiderers who were contracted by the restrictive organizations but not members of the secret production network, as well as some aid agencies operating in the women's local communities. Jalila explained that 'any benefit we receive from [aid agency] will be taken away as they will be suspicious about our income'.

For Jalila, Lubna and Muna, it was also crucial to keep the network and their leadership roles hidden from their families, in-laws and ex-husbands. Reasons given for this were both financial and sociocultural. Initially Jalila, Lubna and Muna's reasoning appeared to be financial, as stated by Lubna:

by law, my ex-husband has to give me a child support allowance which is based on his income and mine. If he discovers my real income, he will take me to court and I will lose the little he gives me.

However, it quickly became apparent that all three women were more concerned with maintaining their ex-husbands' commitment to their children as Muna explained; 'by paying the little he does every month, he stays connected to his children and his responsibilities towards them. By law and in Islam, he is expected to provide for his children even if we are divorced'.

The fragmentation strategy appears to be effective in minimizing the risk of exposure of the hidden network. To date, none of the 'cells' of the secret production network have been exposed, but if one or more were to be, the fragmentation strategy would limit further exposure and damage. Evidently, the five leaders were extremely aware and knowledgeable of their community's gendered social norms, roles and expectations, and strategically navigated these to protect themselves from any damaging consequences of potential exposure of the network. Not only did they take a great risk in creating and maintaining their hidden network, they also proactively strategized to minimize any risk to the network and its members. For example, the leaders relied on their embroidery expertise when communicating with potential clients, and never disclosed their secret production network. Sundos explained, 'all our clients expect only one embroidery expert working on their items. They all say I want you to do this for me because you are the best', Ghalia (Stage 2) added, 'because we have this specialist reputation to maintain, we have to be very strict with the quality control of all the embroiderers, and that is why we are very choosey about who we include in our network'. Thus, 
through their effective organizing, fragmentation strategy, leadership, and risk-taking, these women continued to secure their network's positioning, at least for the near future. The continued success of the network is, however, dependent on the leaders' ongoing collective contractual, social and patriarchal defiance through which, their entrepreneurial leadership thrives.

\section{Discussion and conclusion}

While the literature on women's entrepreneurship largely neglects defiance, the evidence presented in this paper illustrates that the defiance of displaced women entrepreneurs occurs in various guises and in unexpected contexts. The motivation for defying their contextual embeddedness was a necessity for the displaced women's evolving entrepreneurship and perhaps unexpectedly, their motivation was initially the women's willingness to help each other, and secondly, to resist and defy the restrictive organizations, families and community. The outcome of the defiance of the displaced women entrepreneurs is a feminised economy where the founding leaders and members of the secret production network and their clients as well as their restrictive organizations, involve only women converging through the medium of traditional embroidery to express their heritage. Defiance through entrepreneurship is rarely associated with displaced Arab women (Jamali 2009) and our findings about their proactiveness, innovativeness and risk-taking contradict much of the existing literature that portrays them as subservient, disempowered followers rather than defiant entrepreneurial leaders (Yamin 2013). Our findings, therefore, also contribute to this literature and policy regarding the empowerment of displaced women.

The findings revealed strong evidence of the displaced women's contractual, social and patriarchal defiance, and demonstrated how these impacted upon their proactiveness, innovativeness and risk-taking. Indeed, this evidence provides new and non-traditional meanings to mainstream entrepreneurship notions of proactiveness, innovativeness and risk-taking. The proactiveness of the displaced women entrepreneurs in creating and sustaining the secret network was essential for contractual defiance, and their innovativeness through the creative use of feminised space facilitated their social defiance. Through their fragmentation strategy, management and growth of their secret production network, the women took great risks in defying the patriarchal culture in which they operated by creating economic and social independence for themselves and their members.

These findings show how displaced women can envision and enact a strategic and institutionally defiant solution through the creation and management of their secret production network. At the economic level, they offered high-quality products which maintained client relationships. At the social level, they forged secret relationships which further deepened their trust, collaboration, organizing and friendship. At the institutional level they not only created parallel networks to their existing contracts, but also fragmented the network size to keep it manageable and hidden. The women also used to their entrepreneurial advantage the existing social norms for example by meeting in social gatherings. At the familial level, some did not disclose their secret production network to their husbands, in-laws and family members, and an important part of this was the balance they created between their work and family responsibilities.

We firstly contribute to contextualizing displaced women's entrepreneurship by theorizing it within a deeply patriarchal context. Our theorization shows that displaced women's entrepreneurship exists within unexpected places such as highly constrained, deeply patriarchal and masculinized contexts. Whilst the displaced women could not alter the constraints themselves, they creatively circumvented and navigated them by initiating highly imaginative ventures and ingenious strategies in hidden entrepreneurial practices. This suggests that no matter how constrained the context, displaced women entrepreneurs can flourish and prosper if they are prepared to take higher levels of risk through 'hidden' entrepreneurial enactment. Thus, the displaced women's entrepreneurship cannot be restrained, and eventually 'finds its way'.

Secondly, we contribute to entrepreneurship scholarship by extending current understandings of how displaced women defy their contextual embeddedness through entrepreneurship. The 
three dimensions of entrepreneurial orientation - proactiveness, innovativeness and risk-taking are matched with the participants' demonstrated contractual, social and patriarchal, defiance which are embedded in the participants' various actions. Hence, we theorize displaced women's entrepreneurial orientation as an act of defiance to break up constraints and break free from authority, to create and execute new opportunities in uncertain and unknowable environments, and to generate value (economic, social, personal).

Although displaced women in both hidden and visible networks are rarely associated with defiance in the existing discourse (Al-Dajani et al 2015), this paper shows how displaced women can be entrepreneurial, proactively and innovatively defying the institutions that impose limitations and restrictions on them. Doing so raises significant implications for women's entrepreneurship policy and practice. That is, women's entrepreneurship is generally enacted as a strategy to include, embed and rehabilitate socially marginalized women, and to thwart rather than encourage their defiance. As such, recognizing that defiance is an effective catalyst for women's entrepreneurial orientation will require considerable change in mainstream programmes supporting women's entrepreneurship, whether the women are displaced or not.

We are not convinced that the secret production networks, the displaced women's hidden leadership within them, and their defiance, are unique to the displaced women participating in this study (Al-Dajani et al 2015). Rather, these are likely to be established amongst various communities of entrepreneurs, but remain an under-researched phenomenon (Scott 2013) due to the methodological complexities in identifying and engaging 'defiant entrepreneurs' who deliberately choose to remain hidden. Thus, we recommend that future research adopts longitudinal approaches to explore the defiance embedded in entrepreneurship in unexpected places and spaces, to enrich the contextual embeddedness of women's entrepreneurship. Indeed, doing so will not only deepen our understanding and theorizing of women's entrepreneurship, but also of entrepreneurship more broadly.

\section{Disclosure statement}

No potential conflict of interest was reported by the authors.

\section{References}

Ahmad, S. Z. 2011. "Evidence of the Characteristics of Women Entrepreneurs in the Kingdom of Saudi Arabia: An Empirical Investigation." International Journal of Gender and Entrepreneurship 3 (2): 123-143. doi:10.1108/ 17566261111140206.

Al-Dajani, H., S. Carter, E. Shaw, and S. Marlow. 2015. "Entrepreneurship among the Displaced and Dispossessed: Exploring the Limits of Emancipatory Entrepreneuring." British Journal of Management 26 (4): 713-730. doi:10.1111/ 1467-8551.12119.

Al-Dajani, H., and S. Marlow. 2010. “The Impact of Women's Home-Based Enterprise on Marriage Dynamics: Evidence from Jordan." International Small Business Journal 28 (5): 470-487. doi:10.1177/0266242610370392.

Al-Dajani, H., and S. Marlow. 2013. "Empowerment and Entrepreneurship: A Theoretical Framework." International Journal of Entrepreneurial Behaviour and Research 19 (5): 503-524. doi:10.1108/JEBR-10-2011-0138.

Basit, T. N. 1996. "I'd Hate to Be Just a Housewife': Career Aspirations of British Muslim Girls." British Journal of Guidance and Counselling 24 (2): 227-242. doi:10.1080/03069889608260411.

Bird, B., and C. Brush. 2002. "A Gendered Perspective on Organizational Creation." Entrepreneurship Theory and Practice 26 (3): 41-66. doi:10.1177/104225870202600303.

Bolton, L. D., and M. D. Lane. 2012. "Individual Entrepreneurial Orientation: Development of a Measurement Instrument." Education+ Training 54 (2/3): 219-233. doi:10.1108/00400911211210314.

Chamlou, N. 2008. The Environment for Women's Entrepreneurship in the Middle East and North Africa Region. Washington, DC: The World Bank.

Chatelard, G. 2009. Migration from Iraq between the Gulf and Iraq Wars (1990-2003): Historical and Socio-Spatial Dimensions. Working Paper 09-68, COMPAS - Centre on Migration, Policy and Society (Oxford University).

Chhiba, R. D. 2013. "Images of Kali as Reflections of Female Defiance within Selected Examples of Contemporary Asian Arts." Doctoral dissertation, University of the Witwatersrand, Johannesburg. 
Curry, B. K. 2000. Women in Power: Pathways to Leadership in Education. New York, NY: Teachers College Press.

Fanek, F. 2015. "Economic Growth and Unemployment." Jordan Times, December 28.

Gandolfo, L. 2012. Palestinians in Jordan - the Politics of Identity. London: IB Tauris.

Gioia, D. A., K. G. Corley, and A. L. Hamilton. 2013. "Seeking Qualitative Rigor in Inductive Research Notes on the Gioia Methodology." Organizational Research Methods 16 (1): 15-31. doi:10.1177/1094428112452151.

Goheer, N. A. 2003. Women Entrepreneurs in Pakistan. Geneva: International Labour Organization.

Goodman, L. A. 2011. "Comment: On Respondent-Driven Sampling and Snowball Sampling in Hard-to-Reach Populations and Snowball Sampling Not in Hard-to-Reach Populations." Sociological Methodology 41 (1): $347-$ 353. doi:10.1111/j.1467-9531.2011.01242.x.

Goyal, M., and J. Parkash. 2011. "Women Entrepreneurship in India - Problems and Prospects." International Journal of Multidisciplinary Research 1 (5): 195-207.

Habersky, E. 2016. "The Urban Refugee Experience in Jordan." Muftah. Accessed 21 Febuary 2017. http://muftah.org/ the-urban-refugee-experience-in-jordan/\#.WKxvIG-LTIW

Heckathorn, Douglas D. 1977. "Respondent-driven Sampling: A New Approach to the Study of Hidden Populations." Social Problems 44 (2): 174-199.

Henry, C., L. Foss, A. Fayolle, E. Walker, and S. Duffy. 2015. “Entrepreneurial Leadership and Gender: Exploring Theory and Practice in Global Contexts." Journal of Small Business Management 53 (3): 581-586. doi:10.1111/jsbm.2015.53. issue-3.

Hollenbeck, G. P., M. W. McCall Jr, and R. F. Silzer. 2006. “Leadership Competency Models.” The Leadership Quarterly 17 (4): 398-413. doi:10.1016/j.leaqua.2006.04.003.

Hopkins, M. M., D. A. O'Neil, A. Passarelli, and D. Bilimoria. 2008. "Women's Leadership Development Strategic Practices for Women and Organizations." Consulting Psychology Journal: Practice and Research 60 (4): $348-365$. doi:10.1037/a0014093.

Jamali, D. 2009. "Constraints and Opportunities Facing Women Entrepreneurs in Developing Countries." Gender and Management: an International Journal 24 (4): 232-251. doi:10.1108/17542410910961532.

Javadian, G., and R. P. Singh. 2012. "Examining Successful Iranian Women Entrepreneurs: A Exploratory Study." Gender in Management: an International Journal 27 (3): 148-164. doi:10.1108/17542411211221259.

Jordan Department of Statistics. 2016. Annual Statistical Jordan Yearbook. Amman: Department of Statistics.

Kabeer, N. 1999. "Resources, Agency, Achievements: Reflections on the Measurement of Women's Empowerment." Development and Change 30 (3): 435-464. doi:10.1111/dech.1999.30.issue-3.

Kandiyoti, D. 1988. "Bargaining with Patriarchy." Gender \& Society 2 (3): 274-290. doi:10.1177/089124388002003004.

Kark, R. 2004. "The Transformational Leader: Who Is (S)He? A Feminist Perspective." Journal of Organisational Change Management 17 (2): 160-176. doi:10.1108/09534810410530593.

Kiss, A. N., W. M. Danis, and S. T. Cavusgil. 2012. "International Entrepreneurship Research in Emerging Economies: A Critical Review and Research Agenda." Journal of Business Venturing 27 (2): 266-290. doi:10.1016/j. jbusvent.2011.09.004.

Koss, M. P. 2000. "Blame, Shame, and Community: Justice Responses to Violence against Women." American Psychologist 55 (11): 1332-1343. doi:10.1037/0003-066X.55.11.1332.

Kreiser, P. M., and J. Davis. 2010. "Entrepreneurial Orientation and Firm Performance: The Unique Impact of Innovativeness, Proactiveness, and Risk-Taking." Journal of Small Business \& Entrepreneurship 23 (1): 39-51. doi:10.1080/08276331.2010.10593472.

Legatum Prosperity Index. 2016. Accessed 27 September 2017. http://www.prosperity.com/rankings

Liamputtong, P. 2006. Researching the Vulnerable: A Guide to Sensitive Research Methods. London: Sage.

Miles, M. B., A. M. Huberman, and J. Saldaña. 2013. Qualitative Data Analysis: A Methods Sourcebook. London: Sage.

Minkler, M., and N. Wallerstein, Eds. 2010. Community-Based Participatory Research for Health: From Process to Outcomes. San Francisco: Wiley.

Murphy, R. 2015. "Elizabeth Barton's Claim: Feminist Defiance in Wolf Hall." Frontiers: A Journal of Women Studies 36 (2): 152-168. doi:10.5250/fronjwomestud.36.2.0152.

Neck, H. M., and P. G. Greene. 2011. "Entrepreneurship Education: Known Worlds and New Frontiers." Journal of Small Business Management 49 (1): 55-70. doi:10.1111/jsbm.2011.49.issue-1.

Pache, A.-C., and F. Santos. 2010. "When Worlds Collide: The Internal Dynamics of Organisational Responses to Conflicting Institutional Demands." Academy of Management Review 35 (3): 455-476.

Profitt, N. J. 1996. "Battered Women' as 'Victims' and 'Survivors': Creating Space for Resistance." Canadian Social Work Review/Revue Canadienne de Service Social 13: 23-38.

Rindova, V., D. Barry, and D. J. Ketchen. 2009. "Entrepreneuring as Emancipation." Academy of Management Review 34 (3): 477-491. doi:10.5465/amr.2009.40632647.

Scott, C. R. 2013. Anonymous Agencies, Backstreet Businesses, and Covert Collectives: Rethinking Organisations in the 21st Century. Stanford, CA: Stanford University Press.

Stevens, D. 2009. "Legal Status, Labelling, and Protection: The Case of Iraqi 'Refugees' in Jordan." International Journal of Refugee Law 25 (1): 1-38. doi:10.1093/ijrl/eet001. 
Stohl, C., and M. Stohl. 2011. "Secret Agencies: The Communicative Constitution of a Clandestine Organization." Organisation Studies 32 (9): 1197-1215. doi:10.1177/0170840611410839.

Torri, M. C. 2012. “Community Gender Entrepreneurship and Self-Help Groups: A Way Forward to Foster Social Capital and Truly Effective Forms of Participation among Rural Poor Women?" Community Development Journal 47 (1): 58 76. doi:10.1093/cdj/bsq019.

UNHCR. 2016. Global Trends: Forced Displacement in 2015. Geneva: United Nations High Commission for Refugees.

UNRWA. 2010."Jordan Facts." Accessed 15 January 2014. http://www.unrwa.org/etemplate.php?id=66

UNRWA. 2014. "Where We Work." Accessed 21 Febuary 2017. https://www.unrwa.org/where-we-work/jordan

Welter, F. 2011. "Contextualizing Entrepreneurship-Conceptual Challenges and Ways Forward." Entrepreneurship Theory and Practice 35 (1): 165-184. doi:10.1111/etap.2011.35.issue-1.

Welter, F., and D. Smallbone. 2010. "The Embeddedness of Women's Entrepreneurship in a Transition Context." In Women Entrepreneurs and the Global Environment for Growth: A Research Perspective, edited by C. G. Brush, A. De Bruin, E. Gatewood, and C. Henry, 96-117. Cheltenham and Northampton, MA: Edward Elgar.

Yamin, A. 2013. "Jordan Third Largest Refugee Host Worldwide - UNHCR." Jordan Times, December 31, AmmanJordan.

Yousafzai, S. Y., S. Saeed, and M. Muffatto. 2015. "Institutional Theory and Contextual Embeddedness of Women's Entrepreneurial Leadership: Evidence from 92 Countries." Journal of Small Business Management 53 (3): $587-604$. doi:10.1111/jsbm.2015.53.issue-3. 